Jurnal Civics: Media Kajian Kewarganegaraan
https://journal.uny.ac.id/index.php/civics/index
$1829-5789$ (print)
$2541-1918$ (online)

\title{
Penguatan wawasan kebangsaan generasi muda melalui kegiatan tadarus buku
}

\author{
Hendra Saeful Bahri a, ${ }^{*}$, Sapriya ${ }^{\text {b, } 2 \text {, Muhammad Halimi }}{ }^{\text {c, } 3}$ \\ a Sekolah Pascasarjana, Universitas Pendidikan Indonesia, Bandung, Indonesia \\ b, c Fakultas Pendidikan Ilmu Pengetahuan Sosial, Universitas Pendididkan Indonesia, Bandung, Indonesia \\ ${ }^{1}$ hendra.saeful@student.upi.edu*, ${ }^{2}$ sapriya@upi.edu, ${ }^{3}$ mhalimi58@yahoo.com \\ *korespondensi penulis
}

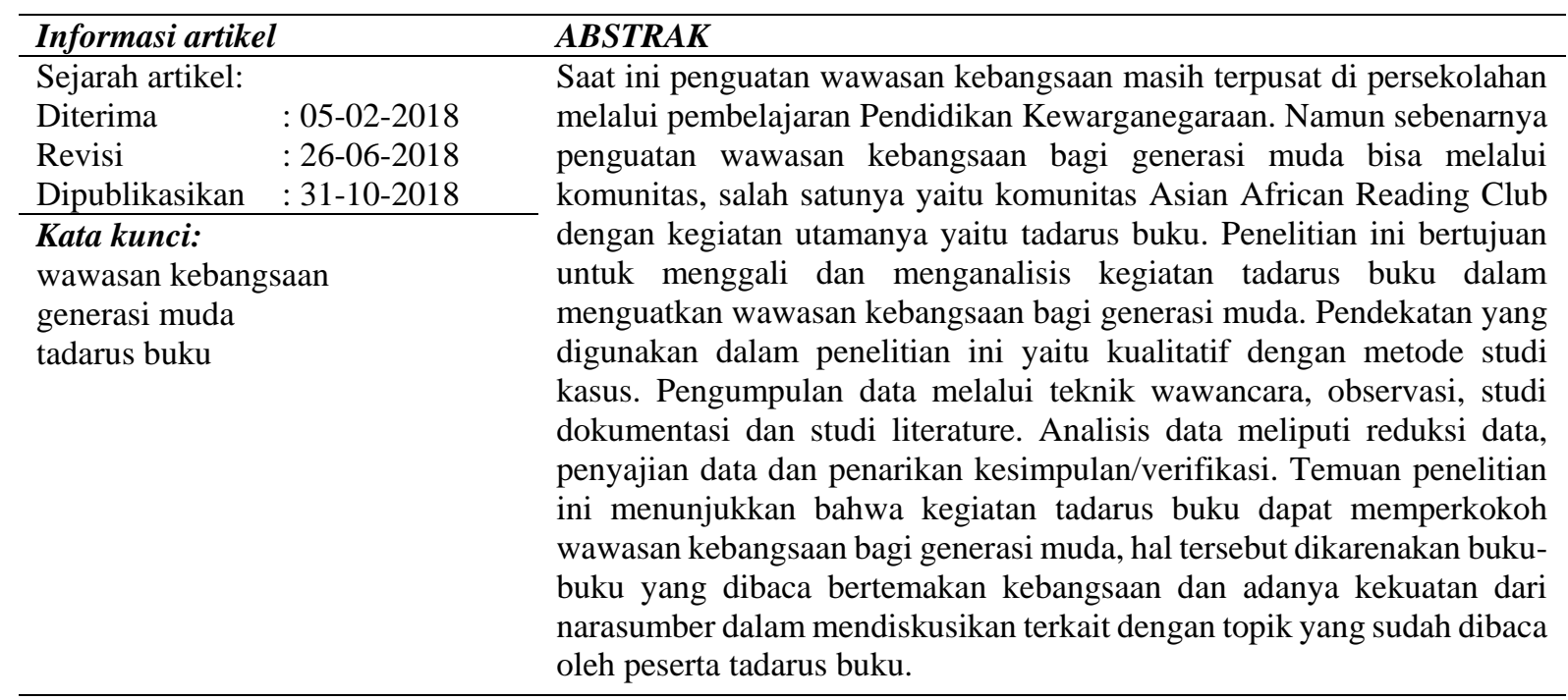

Keywords:

national insight

young generation

tadarus book

\begin{abstract}
At present, the strengthening of nationalism is still centered in schooling through the learning of Citizenship Education. But actually strengthening the national insight for the younger generation can be done through the community, one of which is the Asian African Reading Club community with its main activity is book tadarus. This study aims to explore and analyze reading book activities (Tadarus) in strengthening national insight for the youth. The approach used in this study is qualitative with a case study method. Data collection through interviews, observation, documentation studies, and literature studies. Data analysis includes data reduction, data presentation, and conclusion/verification. The findings of this study indicate that reading book activities (Tadarus) can strengthen national insight for the youth because books are read with the theme of nationality and the power of the speakers in discussing related topics that have been read by participants.
\end{abstract}

\section{Copyright $(2018$ Hendra Saeful Bahri, dkk}

\section{Pendahuluan}

Wawasan Indonesia, khususnya kalangan generasi muda saat ini masih dalam kategori minim. Hal tersebut terlihat dari data Badan Pusat Statistik (BPS) pada tahun 2011 tentang faktor-faktor penyebab timbulnya berbagai permasalahan bangsa, terungkap bahwa persentase masyarakat yang mengatakan setuju bahwa kurangnya kecintaan terhadap Negara Kesatuan Republik Indonesia sebagai salah satu faktor penyebab timbulnya berbagai permasalahan bangsa sekitar $69,80 \%$, sedangkan masyarakat yang mengatakan tidak setuju bahwa kurangnya kecintaan terhadap Negara Kesatuan Republik Indonesia sebagai salah satu faktor penyebab timbulnya berbagai permasalahan bangsa 
sekitar 30,20\% (Badan Pusat Statistik, 2011). Terkait dengan masyarakat yang mengatakan setuju, pada dasarnya sudah mewakili masyarakat Indonesia bahwa kurangnya kecintaan terhadap Negara Kesatuan Republik Indonesia sebagai salah satu faktor penyebab timbulnya berbagai permasalahan bangsa. Jadi pada intinya kurangnya kecintaan masyarakat Indonesia terhadap Negara Kesatuan Republik Indonesia dapat dikatakan sebagai implikasi dari masih minimnya wawasan kebangsaan terkhusus di kalangan generasi muda.

Masalah wawasan kebangsaan yang terjadi pada era sekarang ini, apabila dibiarkan tanpa disertai usaha untuk memperkokoh kembali wawasan kebangsaan maka bangsa Indonesia akan kehilangan jati diri bangsa dan eksistensi pada tataran dunia internasional serta tidak akan terwujudnya hidup damai secara berdampingan di kehidupan masyarakat, berbangsa dan bernegara. Hal ini diperlukan penguasaan wawasan kebangsaan dari seluruh masyarakat Indonesia guna terwujudnya masyarakat yang memahami masalah-masalah global, mempunyai keterampilan untuk mengatasi konflik secara konstruktif, mengenal dan hidup dengan standar internasional tentang kesetaraan hak-hak manusia dan ras, menghargai keragaman budaya dan menghargai kesatuan dunia (Barida, 2017). Oleh karena itu, berkaitan dan kemelekan warga negara ini pada akhirnya menunjukkan pemahaman warga negara dalam proses politik dan pemerintahan, lokal dan nasional yang mengerti hak dan kewajibannya dan selalu berpartisipasi secara efektif dalam kehidupan bermasyarakat lokal, nasional dan internasional (Partnership for 21st Century Skills, 2014; Salpeter, 2008).

Dewasa ini untuk memperkokoh wawasan kebangsaan bagi generasi muda masih terpusat pada pendidikan formal melalui mata pelajaran Pendidikan Pancasila dan Kewarganegaraan (PPKn). Namun, apabila dikaji lebih dalam dan komprehensif untuk memperkokoh wawasan kebangsaan tidak cukup melalui pendidikan formal saja, melainkan harus ditunjang melalui pendidikan informal seperti melalui komunitas- komunitas yang ada di masyarakat. Pendidikan kewarganegaraan harus mampu untuk mengembangkan identitasnya dan keterikatan pada komunitas global (Banks, 2008). Oleh sebab itu, pendidikan kewarganegaraan berperan membangun generasi muda menjadi warga negara yang baik dan cerdas.

Komunitas dapat dimaknai sebagai sebuah kelompok gerakan sosial yang terdiri dari beberapa individu dengan dasar ada kesamaan tempat tinggal, kesamaan interest atau values, kesamaan pemikiran untuk mencapai tujuan tertentu. Gerakan sosial yang dilakukan oleh komunitas melalui tindakan kolektif menjadikan adanya tatanan tradisi baru. Selain itu rasa keanggotaan atas kolektifitas yang ada menimbulkan rasa memiliki diantara anggota komunitas (Blackshaw, 2010).

Berkaitan dengan komunitas, Bandung sebagai kota pintar (smart city) dan kota kreatif memiliki nuansa yang kaya akan komunitas, termasuk yang bergerak di bidang literasi di dalamnya. Literasi merupakan sarana penting komunikasi yang memungkinkan individu, masyarakat dan lembaga untuk berinteraksi, dari waktu ke waktu dan di seluruh ruang, karena mereka mengembangkan jaringan hubungan sosial melalui bahasa (Benavot, 2015). Dalam konteks politik, ketika literasi disandingkan dengan civic menjadi civic literacy merupakan keniscayaan seiring dengan perubahan politik yang menuntut warga bertindak otonom (Suryadi, 2010, hal. 3). Tumbuh kembangnya pelbagai komunitas bidang literasi yang berada di kawasan Kota Bandung merupakan upaya untuk menggelorakan kembali budaya literasi di kalangan generasi muda. Keberadaan komunitas-komunitas tersebut dalam kajian pendidikan kewarganegaraan dikenal dengan konsep "situs kewarganegaraan", dan ada pula yang mengatakan bahwa keberadaan komunitas di masyarakat sebagai bagian dari civic community. Komunitas bidang literasi di Bandung fokus terhadap konteks kebangsaan yaitu Asian African Reading Club (AARC) dengan kegiatan utama "Tadarus Buku". 
Dari berbagai uraian di atas, maka permasalahan yang diangkat yakni memperkokoh wawasan kebangsaan bagi generasi muda melalui kegiatan tadarus dengan tujuan untuk menggali dan menganalisis kegiatan tadarus buku yang diselenggarakan oleh komunitas Asian African Reading Club dalam menguatkan wawasan kebangsaan bagi generasi muda.

\section{Metode}

Untuk memperoleh data digunakan pendekatan penelitian kualitatif dengan metode penelitian studi kasus karena berkaitan dengan peristiwa-peristiwa yang sedang berlangsung dan berkenaan dengan kondisi masa sekarang. Sedangkan teknik pengumpulan data dalam menggunakan teknik wawancara, observasi, studi dokumentasi dan studi literature. Untuk mendapatkan data yang kredibel, maka ada beberapa proses yang dilakukan, yakni proses triangulasi dan member check. Pada proses triangulasi, jenis triangulasi yang digunakan yaitu triangulasi teknik yang meliputi wawancara, observasi, dan studi dokumentasi. Kemudian triangulasi sumber data yang meliputi pendiri, sekretaris jenderal dan peserta kegiatan tadarus buku di komunitas Asian African Reading Club (AARC). Kemudian proses selanjutnya guna mendapatkan data yang kredibel yaitu proses member check. Pada tahap member check ini dilakukan konfirmasi kepada setiap informan di akhir wawancara dengan menyebutkan garis besarnya dengan maksud agar informan memperbaiki bila ada kekeliruan, atau menambahkan apa yang masih kurang (Sugiyono, 2012).

\section{Hasil dan Pembahasan}

Penguatan wawasan kebangsaan merupakan suatu hal harus dilakukan secara terus menerus sejalan dengan dinamika proses kehidupan berbangsa dan bernegara. Begitu pentingnya pemahaman wawasan kebangsaan bagi kalangan generasi muda akan berimplikasi terhadap eksistensi negara pada masa yang akan datang, maju mundurnya suatu negara, dan semangat kehidupan berbangsa dan bernegara. Jadi, pada dasarnya jika terjadi degradasi semangat persatuan dan kesatuan, yang tertinggal hanyalah kelompokkelompok kecil yang berdasarkan suku, agama, kedaerahan, homogeni ke dalam, eksklusif keluar, baginya kebangsaan kata yang kosong. Maka tepat kalau primordialisme, eksklusif pada suku, etnik, daerah, agama yang tidak lagi merasakan kebangsaan dan kegembiraan dalam kebersamaan nasional.

Berkaitan dengan penguatan wawasan kebangsaan, penguatan wawasan kebangsaan bagi generasi muda saat ini masih terpusat di pendidikan formal melalui pembelajaran Pendidikan Pancasila dan Kewarganegaraan (PPKn). Hal tersebut dikarenakan mata pelajaran PPKn memiliki peran strategis dalam memperkokoh wawasan kebangsaan bagi generasi muda. Sebagaimana yang termuat dalam Undang-Undang No. 20 Tahun 2003 tentang Sistem Pendidikan Nasional pada pasal 37 ayat (1) bahwa "Pendidikan Kewarganegaraan dimaksudkan untuk membentuk peserta didik menjadi manusia yang memiliki rasa kebangsaan dan cinta tanah air". Pada intinya salah satu tujuan dari mata pelajaran PPKn adalah membentuk generasi muda untuk memiliki rasa kebangsaan dan cinta tanah air.

Hal yang sama juga diungkapkan oleh Sofyan dan Sundawa (2016) bahwa penerapan mata kuliah Pendidikan Kewarganegaraan sebagai mata kuliah dasar umum yang tergabung dalam mata kuliah pengembangan kepribadian di perguruan tinggi yang diterapkan di lingkungan Sekolah Tinggi Keguruan dan Ilmu Pendidikan Garut memiliki hubungan yang kuat dan memberikan kontribusi yang besar dalam peningkatan wawasan kebangsaan dan semangat nasionalisme bagi mahasiswanya. Dengan demikian terlihat jelas bahwa Pendidikan Kewarganegaraan memiliki hubungan yang sangat erat dalam memperkokoh wawasan kebangsaan dan semangat nasionalisme generasi muda. Namun, apabila dikaji lebih dalam dan komprehensif dalam memperkokoh wawasan kebangsaan tidak cukup melalui pendidikan formal saja, melainkan harus ditunjang melalui pendidikan informal. Seperti melalui 
komunitas yang ada di masyarakat. Salah satu komunitas yang bergerak di bidang literasi dan mempunyai irisan dengan wawasan kebangsaan yaitu komunitas Asian African Reading Club (AARC), dengan kegiatan utamanya yaitu "Tadarus Buku".

Apabila dikaitkan dengan pendidikan, keberadaan komunitas dipandang sebagai bagian dari pengembangan Pendidikan Kewarganegaraan pada domain sosio-kultural dan dikenal dengan nama civic community. Pada dasarnya komunitas ini berperan sebagai media bagi warga negara untuk mengaktualisasikan di dalam kehidupan bermasyarakat akan konsep-konsep yang telah diajarkan di lembaga persekolahan melalui mata pelajaran PPKn mulai dari tingkat dasar sampai tingkat tinggi. Sementara itu civic community terbentuk bertujuan untuk menyelesaikan permasalahan publik yang syarat akan nilai kesukarelaan dan dikaji sebagai sumber dari lahirnya active citizenship dan ekspresi dari partisipasi warga negara. Warga negara tidak hanya memahami kewarganegaraan sebagai status pasif yang mereka dapatkan dari negara melainkan telah sampai pada tahapan memahami secara aktif melalui realisasi berupa tindakan di masyarakat (Wahab \& Sapriya, 2011). Selain itu, civic community juga memiliki karakteristik diantaranya (1) adanya keterlibatan aktif dalam urusan publik; (2) rasa solidaritas, kepercayaan, dan toleransi yang kuat antara anggota komunitas; (3) kesetaraan yang mengikat orang-orang bersama-sama melalui hubungan horizontal yang timbal balik; dan (4) komitmen terhadap kerja sama yang diungkapkan melalui semangat asosiasi lokal akan sosial (Bankoff, 2012). Keberadaan komunitas di lingkungan masyarakat memberi warna tersendiri yang menunjukkan bahwa manusia pada hakekatnya tidak dapat melepaskan perannya sebagai makhluk sosial. Kemudian dalam konteks kewarganegaraan, konsep dari civic community menjadi sebuah bentuk pengembangan komunitas yang lebih kompleks.

Berdasar pada uraian terkait dengan civic community di atas, dapat dikatakan bahwa komunitas AARC merupakan bagian dari civic community. Hal tersebut karena komunitas ini sudah memenuhi karakteristik dari civic community, yaitu (1) memiliki tujuan untuk menyelesaikan masalah publik yang syarat akan nilai kesukarelaan; (2) adanya keterlibatan aktif dalam urusan publik; (3) adanya rasa solidaritas, kepercayaan, dan toleransi yang kuat antara anggota komunitas, dan (4) adanya kesetaraan yang mengikat orang-orang bersama-sama melalui hubungan horizontal yang timbal balik.

Pada dasarnya kehadiran civic community di lingkungan masyarakat bertujuan untuk mengatasi permasalahan sosial dan memfasilitasi keterlibatan masyarakat, hal tersebut sebagaimana yang diungkapkan oleh Doucet \& Lee (2015) bahwa aksi sosial yang positif dalam hal ini civic community merupakan hasil interaksi antara faktor-faktor kultural dan struktural yang membentuk struktur sosial yang mampu secara efektif mengatasi masalah sosial. Perspektif civic community tersebut pada umumnya terdapat dalam dimensi civic community yakni (1) pentingnya kapitalisme lokal dan kelas menengah independen secara ekonomi; (2) struktur masyarakat sipil dan peran mereka dalam memfasilitasi keterlibatan masyarakat; dan (3) stabilitas daerah tempat tinggal dan investasi lokal. (Doucet \& Lee, 2015).

Berkaitan dengan kegiatan tadarus buku yang diselenggarakan oleh komunitas AARC, pelaksanaan kegiatan tadarus buku yang rutin dilaksanakan di gedung KAA bandung ini selalu diawali dengan berdoa kepada Tuhan Yang Maha Esa sesuai dengan agama dan kepercayaan masing-masing peserta tadarus buku yang dipimpin oleh sekretaris jenderal AARC. Setelah berdoa selesai dilaksanakan, kemudian dilanjutkan dengan menggelar kegiatan tadarus buku, yakni pembacaan buku yang dilakukan secara bergiliran dari satu peserta ke peserta lainnya. Biasanya setiap peserta tadarus buku mendapatkan kesempatan satu halaman dari buku yang telah disepakati untuk dikaji Kebanyakan buku yang dikaji merupakan buah pikiran dan karya tokoh-tokoh nasional atau tokoh yang terlibat dalam Konferensi Asia Afrika, seperti (1) The Bandung Connection karya Roeslan Abdulgani; (2) Tonggak-Tonggak di 
Perjalananku karya Ali Sastroamidjojo; (3) Bandung Ibukota Asia-Afrika karya AARC; (4) Pasang Naik Kulit Berwarna karya L.Stoddard; (5) Islam dan Sosialisme karya HOS Tjokroaminoto; (6) Demokrasi Kita karya Bung Hatta; (7) Renungan Indonesia karya sutan Sjahrir; (8) Korupsi karya Tahar Ben Jelloun; (9) Sejarah Afrika karya Darsiti Soeratman; (10) Buku 100 Tahun Haji Agus Salim; (11) 6000 Tahun Sang Merah Putih karya Muhammad Yamin.

Buku-buku yang dibaca dan dikaji pada umumnya sangat relevan dengan penguatan wawasan kebangsaan karena buku-bukunya bertema kebangsaan dan ada nilai-nilai yang bisa teraktualisasikan dalam kehidupan sehari-hari dengan konteks kekinian. Penguatan wawasan kebangsaan melalui kegiatan tadarus buku merupakan suatu strategi dalam memperkuat wawasan kebangsaan dengan media melalui karyakarya sastra dalam wujud buku. Di samping melalui dokumen kesejarahan, gagasan, konsep, dan pandangan tersebut juga dapat ditelusuri melalui karya-karya budaya. Salah satu wujud hasil kebudayaan tersebut adalah karya sastra.

Wawasan kebangsaan dapat dimaknai sebagai cara pandang bangsa Indonesia berdasarkan Pancasila dan Undang-Undang Dasar Negara Republik Indonesia Tahun 1945 tentang diri dan lingkungannya dalam mengekspresikan jati diri bangsa di tengah tatanan kehidupan dunia. Wawasan kebangsaan juga mencerminkan hasrat bangsa Indonesia sebagai bangsa yang merdeka, bersatu, berdaulat, adil dan makmur dalam kebersamaan untuk mengatasi semua hambatan dan tantangan, baik dari luar maupun dari dalam negeri, termasuk rasa kebersamaan dalam menghadapi ancaman separatisme dan radikalisme yang dapat membahayakan persatuan dan kesatuan bangsa (Lemhannas, 2013).

Kegiatan tadarus merupakan kegiatan membaca di suatu majelis dengan strategi membaca secara bergiliran, yang satu membaca dan yang lainnya menyimak serta didampingi oleh orang yang kompeten terhadap isi buku yang sedang dibaca. Membaca merupakan sesuatu yang vital dalam suatu masyarakat terpelajar. Membaca semakin penting dalam kehidupan masyarakat yang semakin kompleks, hal tersebut dikarenakan setiap aspek kehidupan melibatkan kegiatan membaca. Pada dasarnya kegiatan membaca merupakan embrio untuk memperoleh khasanah pengetahuan, dan kegiatan sepanjang hayat manusia. Lebih jauh Sybil (Otike, 2011) mendefinisikan membaca sebagai proses komunikasi melalui pembelajaran formal yang melibatkan pemahaman bahasa tertulis dan menanggapi pesan penulis. Oleh karena itu, ini berarti bahwa ketika seseorang membaca seseorang harus berpikir, memprediksi, mempertanyakan, mengevaluasi dan mendefinisikan. Kegiatan membaca tidak hanya proses pengadopsian huruf, penerjemahan, dan mengetahui isi bacaan, melainkan lebih dari itu. Dengan membaca dapat meningkatkan material dan intelektual manusia itu sendiri.

Untuk mencapai manfaat dari membaca, maka setiap individu tidak cukup hanya dengan membaca kata demi kata saja, melainkan harus mencapai pada tahap pemahaman isi sebuah buku yang dibacanya. Seorang pembaca harus membayangkan apa yang sedang dia baca, memahami apa yang diperdebatkan dalam teks yang dia baca, memahami penghubung antara pikiranpikiran di dalamnya, mengaturnya dengan membandingkan dengan apa yang telah dia kumpulkan sejauh ini, merestrukturisasi pengetahuannya saat ini dengan apa yang telah dia baca, dan memilah apa yang ingin dia simpan dalam pikirannya (Karadeniz \& Can, 2015).

Berkaitan dengan membaca, kegiatan membaca merupakan bagian dari literasi. Sebagaimana yang dikemukakan oleh Alwasilah (2012) bahwa dari dimensi keterampilan, literasi meliputi membaca, menulis, menghitung dan berbicara. Literasi juga merupakan sumber daya mendasar yang sangat berkorelasi dengan pencapaian pendidikan yang secara umum menggunakan informasi cetak dan tulis untuk berfungsi dalam masyarakat, untuk mencapai tujuan seseorang, dan untuk mengembangkan pengetahuan dan potensi seseorang untuk 
mencapai tujuan yang diinginkan dalam interaksi yang tak terhitung jumlahnya yang membentuk kehidupan sehari-hari (Nguyen et al., 2017). Pernyataan Nguyen dkk diperkuat Artieda (2017), bahwa strong literacy skills are essential in all walks of life: from health to work and from school to social life, people with low levels of literacy are more likely to suffer poor health and unemployment, as well as school dropout and an increased risk of poverty. Dengan demikian, kegiatan literacy membaca buku sangat berimplikasi terhadap pencapaian tujuan yang diinginkan dalam kehidupan sehari-hari, mulai dari kesehatan, pekerjaan dan tingkat Pendidikan. Di lain hal, Doležalová (2015) juga menyatakan bahwa reading literacy berarti membaca keaksaraan adalah kompetensi transversal yang penting untuk kehidupan pribadi, profesional dan publik, dan dianggap sebagai sarana pengembangan kepribadian dan masyarakat secara keseluruhan.

Berdasar pada hasil penelitian terungkap bahwa ada keunikan tersendiri dari kegiatan tadarus buku di komunitas Asian African Reading Club (AARC), keunikan tersebut yaitu ada perbedaan dari segi cara membaca buku dari tiap-tiap peserta, ada yang membacanya seperti membaca naskah puisi, seperti membaca berita, penuh semangat, ada pula yang biasa saja. Semuanya bebas berekspresi sesuai dengan kata hati mereka dalam membaca isi buku. Karena anggota Asian African Reading Club (AARC) sendiri terdiri dari berbagai usia mulai dari 18-57 tahun dengan berbagai latar belakang profesi mulai dari mahasiswa, seniman, pedagang buku, budayawan, pekerja swasta, maupun pegawai negeri sipil (PNS).

Setelah selesai membaca buku, kemudian dilanjutkan dengan sesi berikutnya yaitu sesi pembahasan atau diskusi dari buku yang telah dibaca. Pada sesi pembahasan ini selalu diawali dengan berdoa kepada Tuhan Yang Maha Esa dan dilanjutkan dengan menyanyikan lagu kebangsaan Indonesia Raya yang 3 stanzas. Hal tersebut bertujuan untuk selalu mengingat kepada Tuhan Yang Maha Esa dan menumbuhkan jiwa nasionalisme yang tinggi kepada tanah air tercinta. Sesi pembahasan ini biasanya menghadirkan sejarawan, budayawan maupun dosen yang kompeten dengan materi yang akan didiskusikan, agar mereka yang hadir dapat memahami isi dan maksud dari buku serta mengangkat nilai-nilai yang bisa teraktualisasikan dalam kehidupan seharihari, selain itu supaya peserta tadarus buku semakin mengenal penulis dari buku-buku yang dibaca.

Terdapat kekuatan dari pembahas dalam mendiskusikan materi sesuai dengan topik yang telah dibaca oleh peserta tadarus buku. Kekuatan tersebut yaitu pembahas bisa memantik peserta tadarus buku untuk aktif dalam berdiskusi dan pembahasannya selalu membangkitkan rasa dan semangat kebangsaan peserta tadarus buku. Selain itu, buku yang telah disepakati untuk didaras (dikaji) tidak bisa dikhatamkan (diselesaikan) dalam satu kali tadarusan, biasanya beberapa kali tadarusan buku tersebut baru bisa dikhatamkan tergantung dari ketebalan buku dan peserta tadarus yang datang. Setelah buku dikhatamkan maka akan diadakan syukuran khataman, layaknya seperti khataman tadarusan Al Quran.

Pada intinya dari kegiatan tadarus buku ini ada dua hal yang bisa diambil terkait dengan wawasan kebangsaan. Pertama, bisa memperkokoh paham kebangsaan melalui kegiatan membaca bukunya. Kedua, bisa memperkokoh rasa dan semangat kebangsaan melalui diskusi setelah kegiatan membaca atau tadarus buku dilaksanakan. Ketiga, rasa kebangsaan, paham kebangsaan dan semangat kebangsaan.

Rasa kebangsaan merupakan kesadaran bangsa yang tumbuh secara alamiah dalam diri orang seorang karena kebersamaan sosial yang berkembang dari kebudayaan, sejarah dan aspirasi perjuangan. Rasionalisasi rasa kebangsaan akan melahirkan paham kebangsaan, yaitu pikiran-pikiran nasional tentang hakikat dan cita-cita kehidupan dan perjuangan yang menjadi ciri khas bangsa tersebut. Rasa dan paham kebangsaan secara bersama akan mengobarkan semangat kebangsaan yang merupakan tekad dari seluruh masyarakat bangsa tersebut untuk melawan semua ancaman dan rela berkorban bagi kepentingan bangsa dan negara. 
Wawasan membentuk orientasi, persepsi, sikap dan perilaku yang dihayati bersama oleh seluruh rakyat dan bangsa bahwa mereka itu satu.

Berkaitan dengan semangat kebangsaan, semangat kebangsaan (nasionalisme) sangat penting sekali bagi generasi muda Indonesia untuk bisa menjadi bangsa yang maju, bangsa yang modern, bangsa yang aman, dan damai, adil dan sejahtera di tengah-tengah arus globalisasi yang semakin hari semakin menantang negara Indonesia. Sebagai bangsa dan negara di tengah bangsa lain di dunia, Indonesia membutuhkan identitas kebangsaan yang tinggi dari warga negara khususnya di kalangan generasi muda Indonesia. Semangat kebangsaan (nasionalisme) dibutuhkan agar bangsa dan negara Indonesia tetap eksis. Nasionalisme yang tinggi dari warga negara atau generasi muda sehingga akan membuat perilaku positif dan terbaik untuk bangsa dan negara (Amrah, 2016)

Kegiatan membaca buku sebenarnya banyak manfaat yang bisa didapat, mulai dari semakin tahu berbagai macam hal dan menolak lupa. Selain itu, mengubah pola pikir, pola pandang, dan pola sikap. Membaca menumbuhkan pertumbuhan pribadi, moral, dan intelektual pembaca, sumber inspirasi, dan hiburan, dan memberi wawasan tentang diri kita dan orang lain (Ruterana, 2012). Dari beberapa uraian yang sebagaimana tersurat di atas, pada intinya kegiatan tadarus buku yang diselenggarakan di komunitas dapat memperkokoh wawasan kebangsaan generasi muda dikarenakan buku-buku yang dibaca bertemakan kebangsaan sehingga dapat memperkokoh paham kebangsaan generasi muda, selain itu adanya kekuatan dari pembahas dalam mendiskusikan terkait dengan materi yang sudah dibaca, sehingga bisa memperkokoh rasa dan semangat kebangsaan generasi muda. Komunitas AARC memiliki tujuan untuk menyuarakan kembali pesan-pesan masa lalu yang mulai dilupakan oleh generasi muda maupun masyarakat luas, yaitu nilai-nilai spirit Bandung yang menjadi pilar dalam konferensi Asia Afrika di Bandung pada tahun 1955. Internalisasi nilai-nilai wawasan kebangsaan di komunitas ini berasal dari beberapa nilai
Dasasila Bandung, nilai-nilai tersebut yaitu memahami good will, kesetaraan, hidup damai berdampingan, dan gotong royong.

\section{Simpulan}

Kegiatan tadarus buku komunitas (AARC) dapat memperkokoh wawasan kebangsaan generasi muda dikarenakan bukubuku yang dibaca adalah buku-buku yang bertemakan kebangsaan. Semangat kebangsaan (nasionalisme) sangat penting sekali bagi generasi muda Indonesia untuk bisa menjadi bangsa yang maju, bangsa yang modern, bangsa yang aman, dan damai, adil dan sejahtera di tengah-tengah arus globalisasi yang semakin hari semakin menantang negara Indonesia. Sehingga dengan membaca buku tersebut dapat memperkokoh paham kebangsaan generasi muda, selain itu adanya kekuatan dari pembahas dalam mendiskusikan terkait dengan materi yang sudah dibaca, sehingga bisa memantik rasa dan semangat kebangsaan generasi muda.

\section{Ucapan Terima Kasih}

Terima kasih penulis sampaikan kepada komunitas Asian African Reading Club (AARC) yang telah berpartisipasi dan mendukung penulis dalam melakukan penelitian.

\section{Referensi}

Alwasilah, A. C. (2012). Pokoknya rekayasa literasi. Bandung: Kiblat Buku Utama.

Amrah. (2016). Mengulik pengembangan nasionalisme generasi muda di era globalisasi. Jurnal Publikasi Pendidikan, 6(2), 90-87.

Artieda, G. (2017). The role of L1 literacy and reading habits on the $\mathrm{L} 2$ achievement of adult learners of English as a foreign language. System, 66, 168-176. https://doi.org/10.1016/j.system.2017.03 .020

Badan Pusat Statistik. (2011). Laporan hasil survei pandangan masyarakat terhadap kehidupan bernegara. Jakarta.

Bankoff, G. (2012). Storm over san isidro: "Civic community" and disaster risk reduction in the nineteenth century 
Philippines. Journal of History Sociology, 25(3), 331-351.

Banks, J. A. (2008). Diversity, group identity, and citizenship education in a global age. Educational Reseacrh, 37(3), 129-139.

Barida, M. (2017). Inklusivitas vs eksklusivitas: Pentingnya pengembangan wawasan kebangsaan dalam mewujudkan kedamaian yang hakiki bagi masyarakat Indonesia. In THE 5th URECOL PROCEEDING (hal. 1403-1409).

Benavot, A. (2015). Literacy in the 21st century: towards a dynamic nexus of social relations. International Review of Education, 61(3), 273-294. https://doi.org/10.1007/s11159-0159463-3

Blackshaw, T. (2010). Key concept in community studies. London: Sage Publication.

Doležalová, J. (2015). Competencies of teachers and student teachers for the development of reading literacy. Procedia - Social and Behavioral Sciences, $\quad 171$, 519-525. https://doi.org/10.1016/j.sbspro.2015.01 .156

Doucet, J. M., \& Lee, M. R. (2015). Civic communities and urban violence. Social Science Research, 52, 303-316. https://doi.org/10.1016/j.ssresearch.201 5.01 .014

Karadeniz, A., \& Can, R. (2015). A research on book reading habits and media literacy of students at the faculty of education. Procedia - Social and Behavioral Sciences, 174, 4058-4067. https://doi.org/10.1016/j.sbspro.2015.01 .1155

Lemhannas. (2013). Aktualisasi semangat kebangkitan nasional guna memantapkan wawasan kebangsaan lintas generasi dalam rangka ketahanan nasional. Jurnal Kajian Lemhannas RI, 15(1), 30-40.

Nguyen, T. T., Tchetgen Tchetgen, E. J., Kawachi, I., Gilman, S. E., Walter, S., \& Glymour, M. M. (2017). The role of literacy in the association between educational attainment and depressive symptoms. SSM - Population Health, 3(July), 586-593. https://doi.org/10.1016/j.ssmph.2017.07. 002

Otike, F. W. (2011). Reading culture, cultivation and its promotion among pupils : A Kenyan perspective. Reading, 1(August), 1-5.

Partnership for 21st Century Skills. (2014). Reimagining citizenship for the 21st century: a call to action for policymakers and educators. Diambil dari http://www.p21.org/storage/documents/ Reimagining_Citizenship_for_21st_Cen tury_webversion.pdf

Ruterana, P. C. (2012). The making of a reading society: Developing a culture of reading in Rwanda. Linköping University Electronic Press.

Salpeter, J. (2008). 21st century skills: will our students be prepared? Diambil 1 Januari 2016, dari http://www.techlearning.com/article/138 32\%0ALearning

Sofyan, F. S., \& Sundawa, D. (2016). Hubungan mata kuliah Pendidikan Kewarganegaraan dengan peningkatan wawasan kebangsaan dan semangat nasionalisme mahasiswa. Jurnal Pendidikan Ilmu Sosial, 24(2), 185-198.

Sugiyono. (2012). Metode penelitian kuantitatif kualitatif dan $R \& D$. Bandung: Alfabeta.

Suryadi, K. (2010). Inovasi nilai dan fungsi komunikasi partai politik bagi penguatan civic literacy. Pidato Pengukuhan Jabatan Guru Besat Ilmu Komunikasi Politik. Universitas Pendidikan Indonesia, Bandung.

Wahab, A. A., \& Sapriya. (2011). Teori dan landasan Pendidikan Kewarganegaraan. Bandung: Alfabeta. 